\title{
Unravelling the effects of soil and crop management on maize productivity in smallholder agricultural systems of western Kenya-An application of classification and regression tree analysis
}

\author{
P. Tittonell ${ }^{\text {acc, } *}$, K.D. Shepherd ${ }^{\text {b }}$, B. Vanlauwe ${ }^{\text {a }}$, K.E. Giller ${ }^{\text {c }}$ \\ ${ }^{a}$ Tropical Soil Biology and Fertility Institute of the International Centre for Tropical Agriculture (TSBF-CIAT), \\ P.O. Box 30677, Nairobi, Kenya \\ ${ }^{\mathrm{b}}$ World Agroforestry Centre (ICRAF), P.O. Box 30677, Nairobi, Kenya \\ ${ }^{\mathrm{c}}$ Plant Production Systems, Department of Plant Sciences, Wageningen University, P.O. Box 430, \\ 6700 AK Wageningen, The Netherlands
}

Received 18 November 2006; received in revised form 11 May 2007; accepted 20 May 2007

Available online 3 July 2007

\begin{abstract}
To guide soil fertility investment programmes in sub-Saharan Africa, better understanding is needed of the relative importance of soil and crop management factors in determining smallholder crop yields and yield variability. Spatial variability in crop yields within farms is strongly influenced by variation in both current crop management (e.g. planting dates, fertilizer rates) and soil fertility. Variability in soil fertility is in turn strongly influenced by farmers' past soil and crop management. The aim of this study was to investigate the relative importance of soil fertility and crop management factors in determining yield variability and the gap between farmers' maize yields and potential yields in western Kenya. Soil fertility status was assessed on 522 farmers' fields on 60 farms and paired with data on maize-yield and agronomic management for a sub-sample 159 fields. Soil samples were analysed by wet chemistry methods (1/3 of the samples) and also by near infrared diffuse reflectance spectroscopy (all samples). Spectral prediction models for different soil indicators were developed to estimate soil properties for the $2 / 3$ of the samples not analysed by wet chemistry. Because of the complexity of the data set, classification and regression trees (CART) were used to relate crop yields to soil and management factors. Maize grain yields for fields of different soil fertility status as classified by farmers were: poor, 0.5-1.1; medium, 1.0-1.8; high, 1.4-2.5 $\mathrm{t} \mathrm{ha}^{-1}$. The CART analysis showed resource use intensity, planting date, and time of planting were the principal variables determining yield, but at low resource intensity, total soil $\mathrm{N}$ and soil Olsen $\mathrm{P}$ became important yield-determining factors. Only a small group of plots with high average grain yields $\left(2.5 \mathrm{t} \mathrm{ha}^{-1} ; n=8\right)$ was associated with use of nutrient inputs and good plant stands, whereas the largest group with low average yields $\left(1.2 \mathrm{t} \mathrm{ha}^{-1} ; n=90\right)$ was associated with soil Olsen $\mathrm{P}$ values of less than $4 \mathrm{mg} \mathrm{kg}^{-1}$. This classification could be useful as a basis for targeting agronomic advice and inputs to farmers. The results suggest that soil fertility variability patterns on smallholder farms are reinforced by farmers investing more resources on already fertile fields than on infertile fields. CART proved a useful tool for simplifying analysis and providing robust models linking yield to heterogeneous crop management and soil variables.
\end{abstract}

(C) 2007 Elsevier B.V. All rights reserved.

Keywords: Near infrared spectroscopy; Local soil quality indicators; Soil fertility variability; Maize yield; Sub-Saharan Africa

\footnotetext{
* Corresponding author at: Tropical Soil Biology and Fertility Institute of the International Centre for Tropical Agriculture (TSBF-CIAT), P.O. Box 30677, Nairobi, Kenya. Tel.: +254 20 524755; fax: +254 20524763.

E-mail addresses: p.tittonell@cgiar.org, pablo.tittonell@wur.nl (P. Tittonell).
}

\section{Introduction}

It is widely recognized that major investments in improving soil and crop management are required to raise agricultural productivity in sub-Saharan Africa. The 
evidence base is widespread negative nutrient balances on smallholder farms and the large yield gap between potential and actual yields, both observations being causally related (Vanlauwe and Giller, 2006). To help target investment programmes, a better understanding is needed of the relative importance of soil and crop management factors that limit smallholder crop yields and cause large variability in yields within farms. Crop growth potential at a given location is determined by genotype and climate, whereas actual crop yields result from the interactions of local growth-limiting and growth-reducing factors (De Wit, 1992). The variability in crop growth performance within individual farms therefore reflects the effects, interactions and spatial distribution of these factors, many of which are directly influenced by management decisions. Both long-term and current soil management decisions influence the prevailing soil quality, spatio-temporal patterns of resource allocation, and the timing and effectiveness of agronomic practices (e.g. time of planting, weeding).

Crop growth variability within African farming systems has been attributed to: soil properties (e.g. Van Asten, 2003), agronomic practices (e.g. Mutsaers et al., 1995), farmers' resource allocation decisions (e.g. Nkonya et al., 2005), or combinations of these (e.g. Samaké et al., 2006). In western Kenya, agronomic management decisions play an important role in determining resource use efficiency and consequently crop productivity (Tittonell et al., 2007). The gap between potential and actual maize yields is principally caused by limiting factors such as $\mathrm{N}$ and $\mathrm{P}$ availability, and by growthreducing factors such as Striga infestation (Tittonell et al., 2005b). Water availability may also be limiting under conditions of pronounced soil physical degradation, extraordinarily dry years and/or mid-season droughts, resulting in substantial yield losses especially for crops grown on steeply sloping fields subject to run-off (Braun et al., 1997).

In most of these studies, linear regression and correlation techniques have been used to relate crop yield variability to agronomic factors. We hypothesise that the different components of crop growth variability are interdependent, and that their interaction often leads to reinforcing synergistic effects; e.g. when crops are planted late on sloping remote fields of a farm, bare soil surfaces are exposed to erosion, which further degrades the soil. We can expect thresholds to exist in relationships between yield and management or soil fertility variables, leading to nonlinearities. Analysis of such interactions requires application of multivariate analysis methods and an ability to deal with non-linear relationships. Farm survey data sets are normally characterized by a mixture of continuous and categorical variables, highly skewed data, and large numbers of missing observations, adding to the complexity of the analysis.

Classification and regression tree (CART) analysis has increasingly been used in different fields of research for analysis of problems of this nature, as it has a number of advantages over alternative methods, such as multivariate logistic regression (Tsien et al., 1998). Since CART is inherently non-parametric, no assumptions are made regarding the underlying distribution of values of the predictor variables. Thus, CART can handle numerical data that are highly skewed or multi-modal, as well as category predictors with either ordinal or non-ordinal structure. CART has been extensively applied in medical research, as it is ideally suited to the generation of clinical decision rules (e.g. Crichton et al., 1997), and to develop risk assessment tools (e.g. Steadman et al., 2000). CART analysis has rarely been applied in agricultural research. Shepherd and Walsh (2002) used classification trees to relate soil fertility case definitions to reflectance spectra for an extensive library of African soils. CART analysis has also been used to characterise the habitat structure of termites in agroforestry systems (Martius, 2004).

In analysing crop yield variability at farm scale, the use of CART may help to stratify such variability into classes that reflect interactions between crop management and soil fertility, and thus may have practical use for targeting soil and crop management interventions and advice to farmers. For example, the relation between input use and yields (i.e. crop response) has been shown to vary for different soil quality classes (Vanlauwe et al., 2006). These classes can be related to local farmers' soil quality indicators to assist in efficient targeting of resources through fine-tuned decisionmaking. However, the analysis of a sufficiently large number of cases to establish reliable explanatory models requires time-consuming and costly soil analyses, which are rarely feasible. To overcome this limitation, we propose the use of soil analysis by infrared diffuse reflectance spectroscopy (IR) in combination with spectral calibration to conventional wet chemistry methods; soil reflectance itself can also be used as a soil fertility indicator (Shepherd and Walsh, 2002, 2007). With this technique, soil fertility properties can be characterized on about 400 samples a day at low cost.

Our objective was to determine the main environmental and agronomic management factors that determine maize yields on farmers' fields across a range of conditions of soils, climate, population density, and market access in western Kenya. Understanding the relative importance of these factors was deemed a necessary step in contributing to the design of technical interventions to reduce yield gaps for maize, the major food crop in western Kenya. We used CART to unravel the relationships between environmental and agronomic management factors and determine their relative importance as explanatory variables for crop yield variability.

\section{Materials and methods}

\subsection{The study area}

The study included three sites in the highly-populated region of western Kenya: Aludeka division in Teso district $\left(0^{\circ} 35^{\prime} \mathrm{N} ; 34^{\circ} 19^{\prime} \mathrm{E}\right)$, Emuhaya division in Vihiga district $\left(0^{\circ} 4^{\prime} \mathrm{N} ; 34^{\circ} 38^{\prime} \mathrm{E}\right)$ and Shinyalu division in Kakamega district 
$\left(0^{\circ} 12^{\prime} \mathrm{N} ; 34^{\circ} 48^{\prime} \mathrm{E}\right)$, covering an area of $99,420 \mathrm{~km}^{2}(68 \%$ of which is considered of high agricultural potential). Gradients in altitude, rainfall, topography and soil types as well as differences in population density, ethnic groups, access to markets, and land use were observed between these sites, which encompass much of the variability found in the region. Average farm sizes are small (from 0.5 to $2.0 \mathrm{ha}$ ); population density in the rural areas ranges from 300 to 1300 inhabitants $\mathrm{km}^{-2}$ (Kenya Ministry of Agriculture and Rural Development, 2004). Rainfall ranges from 1000 to $2000 \mathrm{~mm}$ annually and is distributed in two cropping seasons in most of the region: the long rains from March to July and the short rains from August to November. The landscape is gently undulating in the East to fairly flat in the West, with the exception of scattered groups of hills. Nitisols, Ferralsols and Acrisols are the predominant soil types (Jaetzold and Schmidt, 1982). The land use systems are diversified and range from subsistence smallholdings to more cash-crop oriented farms, and different types of croplivestock systems can be found across localities and between farmers of different social status. Maize (Zea mays L.), beans (Phaseolus vulgaris L.), sorghum (Sorghum bicolor (L.) Moench), cassava (Manihot esculenta Crantz) and finger millet (Eleusine coracana L.) are the main staple food crops grown in the region. Further details are given by Tittonell et al. $(2005 b, c)$.

\subsection{Field sampling}

In 2002 , on-farm research was conducted in the three locations described above to document the magnitude and

Table 1

Explanatory variables used in the CART analysis

\begin{tabular}{|c|c|c|}
\hline Category & Variables & Detail \\
\hline \multirow[t]{3}{*}{ General } & Site & $\begin{array}{l}\text { Locations within western Kenya: Aludeka (Teso District), Emuhaya (Vihiga District) } \\
\text { and Shinyalu (Kakamega District); average rainfall: c. 1400, } 1700 \text { and } 2000 \mathrm{~mm} \text { respectively. }\end{array}$ \\
\hline & Wealth & Wealth ranking of farms: low, medium and high resource endowment (LRE, MRE and HRE) \\
\hline & FSQC & $\begin{array}{l}\text { Farmers' soil quality class: classification of the different fields of a farm as poor, average and } \\
\text { fertile (each farmer classified their own farm) }\end{array}$ \\
\hline
\end{tabular}

Management $\quad$ RDH

SDP

PLD

Weed

Relative distance from the homestead; relating the distance from the sampling point to the homestead to the maximum distance possible within the farm (furthest field)

Standardised $^{\mathrm{a}}$ delay in the planting date with respect to the optimum for each location Plant population density $\left(\mathrm{pl} \mathrm{m}^{-2}\right)$ of maize

Weed infestation level; score 0 to 3 (absent, low-high). Hand weeding twice in the season is regarded as good practice in the area; maize crops that were absent of weeds at sampling (physiological maturity) but were only weeded once in the season scored Weed $=1$.

Striga

RUI

Striga sp. infestation level; score 0 to 3 (absent, low-high)

Resource use intensity; scores 0 to 3 indicating no, few, medium or high use intensity of nutrient resources (e.g. RUI $=1$ means use of organic or mineral fertilisers at insufficient rates).

Soil and landscape Soil wet chemistry

Silt + Clay, soil organic C (SOC, $\left.\mathrm{g} \mathrm{kg}^{-1}\right)$, total soil $\mathrm{N}\left(\mathrm{Nt}, \mathrm{g} \mathrm{kg}^{-1}\right)$, extractable $\mathrm{P}$

$\left(\right.$ Ext_P, $\left.\mathrm{mg} \mathrm{kg}^{-1}\right)$, exchangeable $\mathrm{K}^{+}, \mathrm{Ca}^{++}$and $\mathrm{Mg}^{++}\left(\mathrm{Exc} \_\mathrm{K}, \mathrm{Exc} \_\mathrm{Ca}\right.$ and Exc_Mg, $\left.\mathrm{cmol}_{(\mathrm{c})} \mathrm{kg}^{-1}\right)$ and soil $\mathrm{pH}$ in water $(1: 2.5)$

Slope $\quad$ Slope of the fields $(\%)$

Soil spectral Principal component scores of the soil spectral data (PCA); principal component of the partial least square regression analysis (PLSR) relating maize yields to the spectra; predicted soil properties using the spectral models (PLSR)

\footnotetext{
${ }^{\text {a }}$ Standardisation was done with respect to the planting date considered optimum for each site (as recommended by local agricultural extension services) to make comparisons across sites possible PCA: principal component analysis; PLSR: partial least square regression.
} 
along a transect together with the farmer and discussed each field in turn, aided by a map of the farm drawn by the farmer. Maize was the main crop grown in ca. $80 \%$ of the fields surveyed. All the fields in the sample of 60 farms $(n=522)$ were classified by farmers into fertile $(22 \%$ of all sampled fields), average $(40 \%)$ or poor $(38 \%)$, and the area of each field was measured using a Global Positioning System (GPS) device. Topsoil (0-15 cm) samples were taken with an auger at five points per field from all the production units identified in each case-study farm; the five (sub-)samples from each field were mixed and one composite sample per field was sent for analysis $(n=522)$. The samples were airdried, passed through a $2 \mathrm{~mm}$ sieve, and stored at room temperature prior to analysis.

Maize yields were estimated on-farm from non-destructive plant morphological measurements, using allometric models described by Tittonell et al. (2005a), in a representative subset of 159 out of the 522 fields that included high- and low-yielding fields (as indicated by farmers). Grain yield was estimated from measurements of plant height, stem diameter, and ear length taken at around the 'milky stage' of maize during the long rains season of 2002. Information on agronomic management practices was recorded, including: the cultivar(s) used, the type and amount of inputs used, timing of crop and soil management activities and their sequential order within the farm, average yields obtained, weed infestation levels (estimated through visual scoring during the cropping season), and general crop husbandry practices adopted (e.g. plant density) including the variables under the category 'Management' in Table 1.

\subsection{Soil analysis}

\subsubsection{Near infrared spectroscopy}

All 522 samples taken from the farms were analysed by diffuse reflectance spectroscopy, using a FieldSpec FR spectroradiometer (Analytical Spectral Devices Inc., Boulder, Colorado) at wavelengths from 0.35 to $2.5 \mu \mathrm{m}$ with a spectral sampling interval of $1 \mathrm{~nm}$ using the optical setup described in Shepherd et al. (2003). Using the spectral library approach described by Shepherd and Walsh (2002), a sub-sample of 190 soils was selected for wet chemistry analysis based on their spectral diversity. This was done by conducting a principal component analysis of the first derivative spectra and computing the Euclidean distance based on the scores of the significant principal components. Random samples were then selected from each quartile of the ranked Euclidean distances to make up the 190 samples for analysis by wet chemistry.

\subsubsection{Wet chemistry analysis}

The 190 selected soil samples were analysed following standard methods for tropical soils (Anderson and Ingram, 1993). Soil $\mathrm{pH}$ was determined in water using a $1: 2.5$ soil/ solution ratio. Samples were extracted with $1 \mathrm{M} \mathrm{KCl}$ using a 1:10 soil/solution ratio, analysed by $\mathrm{NaOH}$ titration for exchangeable acidity and by atomic absorption spectrometry for exchangeable $\mathrm{Ca}$ and $\mathrm{Mg}$. Samples with $\mathrm{pH}>5.5$ were assumed to have zero exchangeable acidity and samples with $\mathrm{pH}<7.5$, zero exchangeable $\mathrm{Na}$ (all samples in this case). Samples were extracted with $0.5 \mathrm{M} \mathrm{NaHCO} \mathrm{N}_{3}+0.01 \mathrm{M}$ EDTA (pH 8.5, modified Olsen) using a 1:10 soil/solution ratio and analysed by flame photometer for exchangeable $\mathrm{K}$ and colorimetrically (molybdenum blue) for extractable P. Organic C (SOC) was determined colorimetrically after $\mathrm{H}_{2} \mathrm{SO}_{4}$ - dichromate oxidation at $150^{\circ} \mathrm{C}$ for $30 \mathrm{~min}$. Total $\mathrm{N}$ was determined by Kjeldahl digestion with sulphuric acid and selenium as a catalyst. Particle-size distribution was determined using the hydrometer method after pre-treatment with $\mathrm{H}_{2} \mathrm{O}_{2}$ to remove organic matter (Gee and Bauder, 1986). Effective cation-exchange capacity (ECEC) was calculated as the sum of exchangeable acidity and exchangeable bases.

\subsection{Exploratory analysis of the soil chemistry and spectral data}

The analysis of the variation in the soil data was performed using Genstat Version 8. The soil variables were transformed (ln or square root) where necessary to obtain a normal distribution, and standardized before analysis. A principal component analysis (PCA) was first done on soil wet chemistry indicators (Silt + Clay, SOC, total $\mathrm{N}$, extractable $\mathrm{P}$ and $\mathrm{K}$, exchangeable $\mathrm{Ca}$ and $\mathrm{Mg}$, and $\mathrm{pH}$; $n=190$ ) to explore their interrelationships. The PCA yielded a model in which three PC's explained $90 \%$ of the variation. PC1, which explained $56 \%$ of the variation, had positive loadings on soil organic $\mathrm{C}$ and exchangeable $\mathrm{Ca}$ and $\mathrm{Mg}$. Total $\mathrm{N}$ was not included in the analysis, as it added little information to the model due to its correlation with soil $\mathrm{C}$ $\left(r^{2}=0.8\right)$. Extractable $\mathrm{P}$ and $\mathrm{K}$, and $\mathrm{pH}$ had positive loadings with PC2, and explained a further $24 \%$ of the variation in the data. PC3 explained a further $10 \%$ of the remaining variation, with large positive loadings on extractable $\mathrm{P}$. The clay + silt content of the soil had intermediate loadings on PC1 and PC2, and was positively and highly correlated with the organic C content ( $r=0.92)$. Secondly, a PCA was done on the first derivative of the soil spectral data to summarise the spectral soil information in a few components. Seven PC's were necessary to explain $95 \%$ of the variance in the soil spectral data, which were then included in the maizesubset database for later use as explanatory variables for maize yield, as an alternative to using predicted soil analytical data (cf. Table 1).

\subsection{Prediction of soil properties from the near infrared spectra}

The wet chemistry variables were transformed when necessary to obtain a normal probability distribution. Partial least squares regression (PLSR), implemented in The Unscrambler (Camo Inc.) was used to calibrate the 
transformed wet chemistry variables to the first derivative of the soil spectral data. Full hold-out-one cross-validation was done to prevent over-fitting and provide error estimates. Jack-knifing was done to exclude 'non-significant' wavebands. Samples with residual $y$ variance $>3$ residual standard deviations were omitted as outliers. Models with reasonable validation results were used to predict the soil properties for the entire sample population $(n=522)$. A fairly good model was obtained for prediction of the clay + silt content, whereas the spectral predictions of soil organic $\mathrm{C}$ and total $\mathrm{N}$ were moderately accurate (Fig. 1). For extractable $\mathrm{P}$ the PLSR model predicted reasonable well in the low range (measured values $<4.5 \mathrm{mg} \mathrm{kg}^{-1}$ ) but tended to under-predict in the high range of extractable $P$ values. The root mean square errors of these predictions calculated on the back-transformed data, and based on full hold-outone cross-validation, were: clay + silt, $22.5 \%$;, $1.7 \mathrm{~g} \mathrm{~kg}^{-1}$; $\mathrm{N}, 0.44 \mathrm{~g} \mathrm{~kg}^{-1}$; available $\mathrm{P}, 5.4 \mathrm{mg} \mathrm{kg}^{-1}$. The validation of the spectral models for exchangeable $\mathrm{K}$, for the effective cation exchange capacity (ECEC), and for $\mathrm{pH}$ (not shown) had $r^{2}$ values of $0.41,0.82$ and 0.67 , respectively, with root mean square errors of prediction: $\mathrm{K}, 0.5 \mathrm{cmol}_{\mathrm{c}} \mathrm{kg}^{-1}$; ECEC, $1.6 \mathrm{cmol}_{\mathrm{c}} \mathrm{kg}^{-1} ; \mathrm{pH}, 0.6$. Additionally, a PLSR was done using the maize-subset $(n=159)$ soil spectral data to predict maize yields using the first derivative of the spectra-a way of 'orientating' the spectra to the yield variation. The analysis was done for the square root transformed maize

(A) Clay plus Silt (\%)

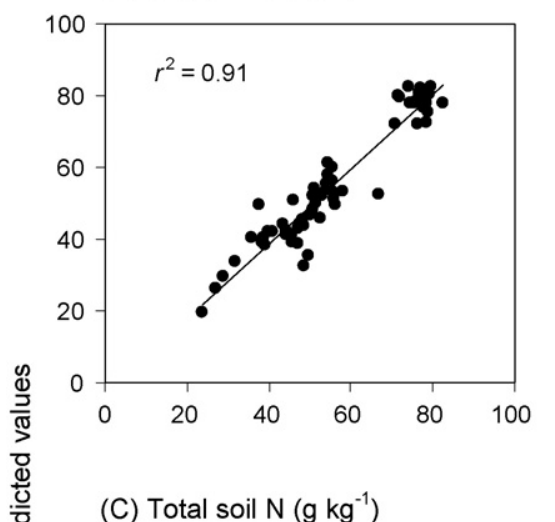

(C) Total soil $\mathrm{N}\left(\mathrm{g} \mathrm{kg}^{-1}\right)$

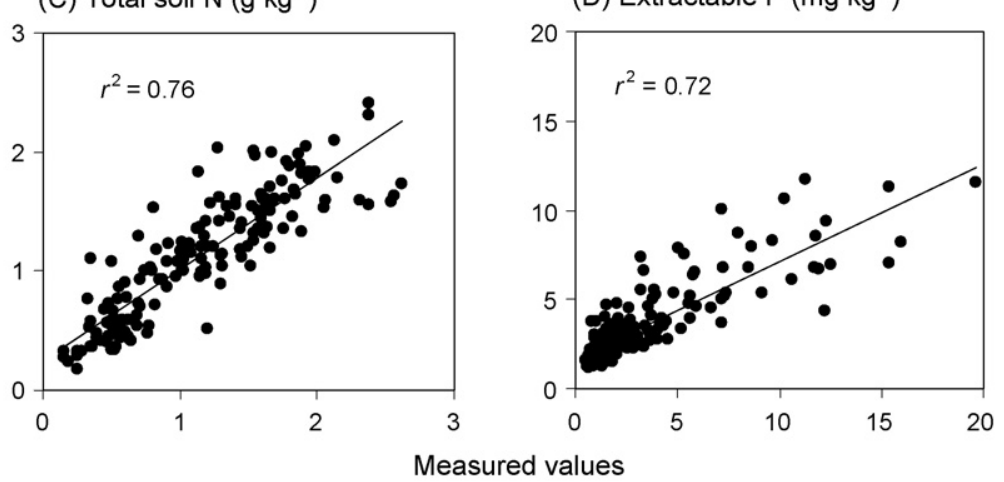

yields as response variable, using the first derivative of the spectra as independent variables. The cross-validated model gave $r^{2}=0.37$, indicating that soil reflectance had some explanatory power in prediction of maize yields. With strong influence of current agronomic management and climatic variation, we would not expect high amounts of variability in yield to be explained by soil quality. These findings, together with those of previous studies (Tittonell et al., 2007), guided us in designing the sequencing of explanatory variables included in the stepwise analysis using CART (cf. 2.6).

\subsection{Classification and regression tree (CART) analysis}

The aim of CART (Salford Systems Inc., San Diego, CA, USA) is to predict or explain the response of a categorical variable (classification trees) or a continuous variable (regression trees) from a set of predictor variables using binary recursive partitioning rules, which are based on thresholds in categorical or continuous predictor variables (Breiman et al., 1984; Steinberg and Cola, 1997). CART has some advantages over more conventional statistical methods: (i) there are no statistical distribution assumptions for dependent and independent variables; (ii) a mixture of categorical and continuous explanatory variables is allowed; (iii) it is not sensitive to outliers, multi-colinearity, heteroskedasticity, or distributional error structures that

(B) Soil organic $\mathrm{C}\left(\mathrm{g} \mathrm{kg}^{-1}\right)$

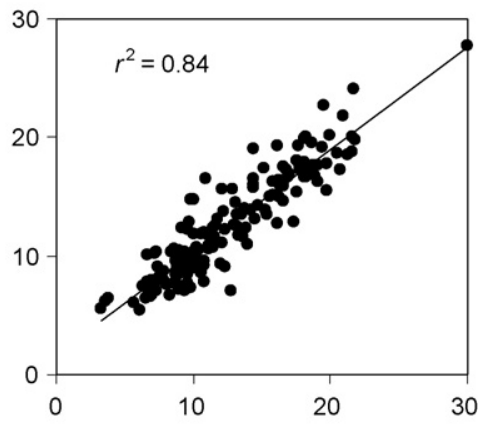

(D) Extractable $P\left(\mathrm{mg} \mathrm{kg}^{-1}\right)$

Fig. 1. Predicted soil fertility indicators using spectral soil analysis plotted against their measured value using standard wet chemistry methods $(n=159$, except A: $n=64)$. 
affect parametric methods; (iv) it has ability to reveal variable interactions. The flexibility CART provides is wellsuited to the problem in this study of uncovering the predictive structure of yield variability from diverse continuous and categorical variables, often having highly skewed distributions.

CART works by automatically searching through alternative values of a predictor variable that maximizes the quality of the split (separation) of the target variable into two 'child' nodes. The optimal splitting rules (e.g. if soil C concentration $<1 \mathrm{~g} \mathrm{~kg}^{-1}$ then assign to left child node) are found using brute force search for all levels of all potential predictor variables. Once a best split is found, CART repeats the search process recursively for each child node, thereby creating a tree structure. CART grows very large trees and then prunes them back to an optimal sized tree based on relative error rates (misclassification error). Error rates are derived using cross-validation or hold-out validation. The trees consist of a number of intermediate, splitting nodes and a series of terminal nodes (TN) that represent homogeneous groups of observations in terms of the response variable (e.g. maize yield). The explanatory variables appear in the consecutive splitting nodes in a hierarchy of decreasing explanatory power. Literature and examples on the use of CART analysis in different branches of science can be found at: http://www.salford-systems.com/.

The CART analyses were performed using the subset of samples for which maize yields were available $(n=159)$. Maize yield variables (grain, biomass, grain yield per plant, biomass per plant) were used as the target variable in turn. In previous studies in this area environmental variables had less explanatory power than management variables (Tittonell et al., 2007). Therefore first management or agronomic practices were tested as explanatory variables together with general site and wealth characteristics, and in a second step soil data (spectral and wet chemistry) were added. Thus CART analyses were done using the following sets of candidate explanatory variables:

\section{CART model1 :}

$$
\begin{aligned}
& \text { Maize yield }=f(\text { General }, \text { Management }) \\
& \text { CART model2: } \quad \text { Maize yield } \\
& \quad=f(\text { General, Management, Soil and landscape })
\end{aligned}
$$

where, 'General', 'Management', 'Soil and landscape' correspond to the groups of variables presented in Table 1. In setting up the analysis, all variables within these three categories are included as candidates and the program automatically chooses the ones with larger explanatory power. The categorical variables Site, Wealth and FSQC were included in all the analyses to account for differences in climate and/or other management-related differences that could have affected crop growth. CART default settings were used. The optimum tree, within one standard deviation of the minimum relative error, was selected using 10-fold cross validation. Further exploratory analysis was conducted by either further pruning (reducing the number of terminal nodes) or growing trees (increasing the number of terminal nodes). Of particular interest is the situation where a more parsimonious tree can be obtained with only small increase in relative error (RE).

The data was first screened for outliers, and 8 out of 159 cases were omitted to avoid having terminal nodes with few observations. For example there were four samples with total soil $\mathrm{N}>2 \mathrm{~g} \mathrm{~kg}^{-1}$ that were often distinguished as a separate group by CART and associated with very high yields $\left(>4 \mathrm{tha}^{-1}\right)$. Variables initially having marked asymmetrical distributions were also transformed into discrete classes to give relatively even distribution of numbers of observations within each class. Most fields sampled had slopes $<5 \%$, some between 5 and $20 \%$, and fewer cases were observed between 20 and $50 \%$. Due to this distribution pattern the continuous variable field slope was transformed into classes of flat $(<2 \%)$, gently undulating $(2-5 \%)$, sloping $(5-20$ or $25 \%)$ and steeply sloping $(>25 \%)$. A similar regrouping was done for the scorings of resource use intensity (RUI) and Striga infestation level; for RUI, samples were reclassified into low (scores 0,1) and high (scores 2,3) intensity, whereas Striga infestation was expressed as "absence" (score 0) and "presence" (score 1-3).

\section{Results}

\subsection{Characterising soil quality and maize yield variability}

Soil properties differed among sites, with Shinyalu having finer textured soils with greater soil $\mathrm{C}$ content and cation exchange capacity, and Aludeka having lowest fertility (Fig. 2). Median extractable P concentrations were strongly deficient in Emuhaya and Shinyalu, at about $2 \mathrm{mg} \mathrm{kg}^{-1}$. Aludeka had a higher median value $\left(4 \mathrm{mg} \mathrm{kg}^{-1}\right)$ and a larger inter-quartile range than the other sites. In general, samples with high extractable $P$ values ( $>12 \mathrm{mg} \mathrm{kg}^{-1}$ ) were from fields close to the homesteads, where ash is commonly added to the soil (see also Tittonell et al. $(2005 \mathrm{~b}, \mathrm{c}))$. The spectral analysis was sufficiently sensitive to capture the variation in soil fertility between the different fields of individual farms, but because there are generally fewer samples with high nutrient levels available for calibration, spectral predictions tend to be poorest in the high range. As expected, different soil quality indicators showed covariation. For example, the samples with high predicted values for available $\mathrm{P}$ were also those with high predicted soil C content (Fig. 3). All samples with available $\mathrm{P}$ above $4.5 \mathrm{mg} \mathrm{kg}^{-1}$ had soil $\mathrm{C}$ contents greater than $8.5 \mathrm{~g} \mathrm{~kg}^{-1}$ (equivalent to $1.5 \%$ of soil organic matter), and they correspond to the points in the zone I in the scatter plot of Fig. 3. Points in the zones II and III of the graph constitute 
Soil clay content $(\%)$
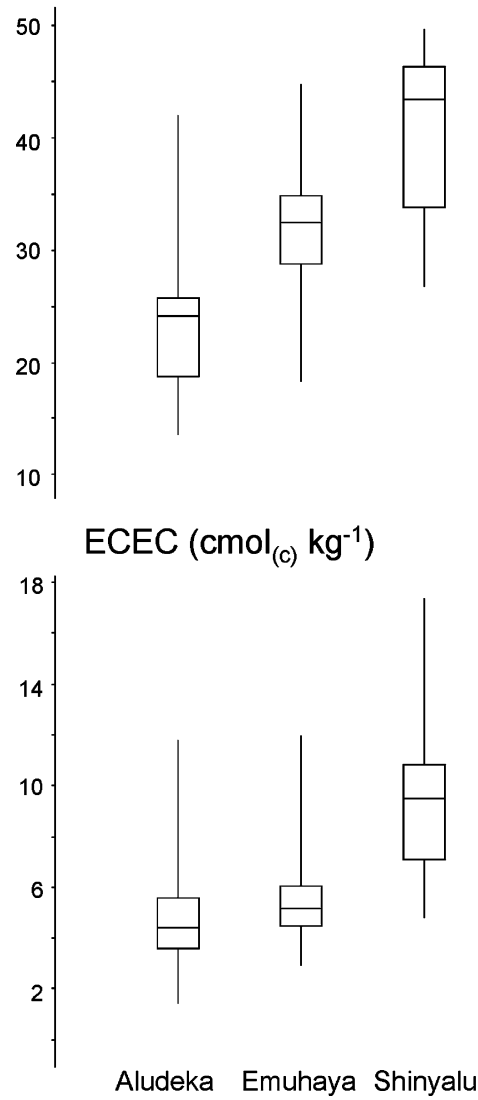

Soil organic $\mathrm{C}\left(\mathrm{g} \mathrm{kg}^{-1}\right)$

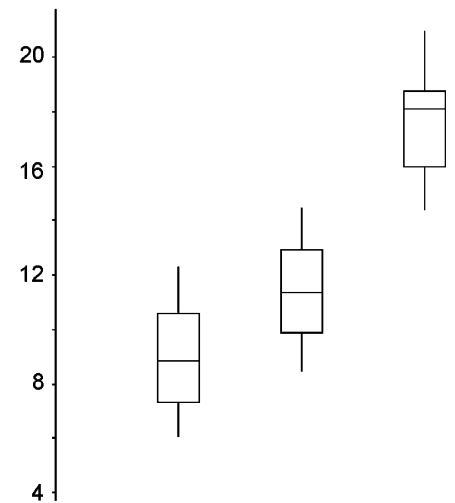

\section{Extractable $\mathrm{P}\left(\mathrm{mg} \mathrm{kg}^{-1}\right)$}

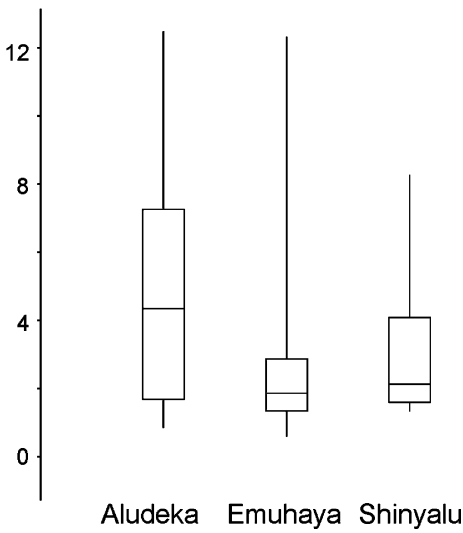

Fig. 2. Range of variation of selected soil properties measured using standard wet chemistry methods across the three sites of western Kenya where the field samplings for maize yield and soil fertility were performed, Aludeka (Teso district), Emuhaya (Vihiga district) and Shinyalu (Kakamega district). The box-andwhisker diagrams include the range of $50 \%$ of the samples (rectangle), the median (cross bar) and the maximum and minimum values (extreme of the lines).

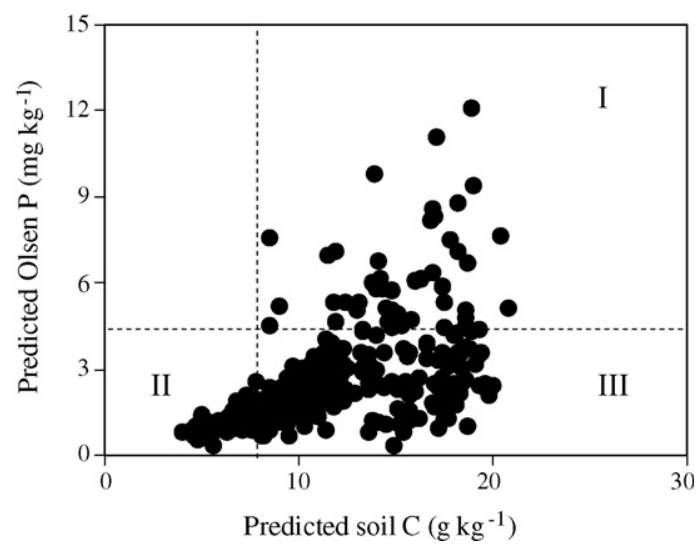

Fig. 3. Spectral predictions of extractable (Olsen) phosphorus vs. predictions of organic carbon in the soils of all the fields sampled $(n=522)$. The dotted lines divide the scatter in three zones such that the observations in Zone I correspond to high extractable $\mathrm{P}\left(>4.5 \mathrm{mg} \mathrm{kg}^{-1}\right.$ ) and high $\mathrm{C}$ (>ca. $\left.8.5 \mathrm{mg} \mathrm{kg}^{-1}\right)$; Zone II corresponds to low extractable $\mathrm{P}$ and low $\mathrm{C}$; Zone III corresponds to low extractable $\mathrm{P}$ and high $\mathrm{C}$. The $\mathrm{P}$ threshold corresponds to the values above which the spectral model showed a weaker predictive capacity; the $\mathrm{C}$ threshold is arbitrary, and was delineated to leave all samples above the $\mathrm{P}$ threshold to the right. the most common cases, corresponding to samples with low available $\mathrm{P}$ values and either low or high soil $\mathrm{C}$ contents, respectively.

Although wide variation in grain yield was observed within each site, average maize grain yields were poorest in Aludeka $(P<0.05)$ (Fig. 4). Only in Emuhaya was there a consistent positive relationship between yield and resource endowment, but yields were least in the low resource endowment category at all three sites. Maize is both a food and a cash crop for MRE farmers in Emuhaia, who often grow it in the best soils of the farm (Tittonell et al., 2005b). Although each individual farmer classified their own soils as fertile to poor, using their own indicators, maize yields varied quite consistently between soil quality classes across sites (and farm types). The largest variability in maize yields was observed for the fields classified as poor, for which the coefficient of variation of the measured yields ranged from 70 to more than $100 \%$. In general, the maize yields measured on the sampled farms were much lower than those achieved in on-station trials under controlled conditions (e.g. 6-7 $\mathrm{t} \mathrm{ha}^{-1}$; FURP, 1994), which are close to the potential yields for this agro-ecological zone in western Kenya. 


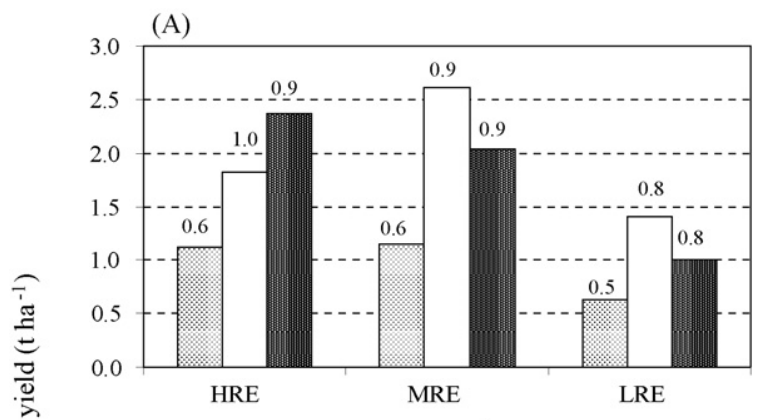

(B) Farm resource endowment

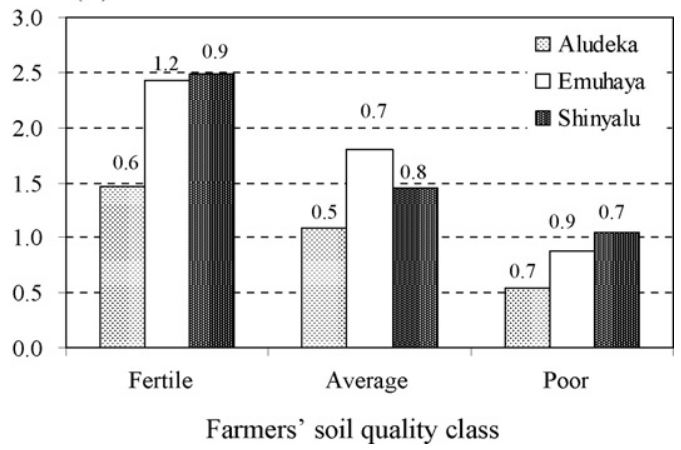

Fig. 4. Variation of maize grain yields between farms of different resource endowment (A) and across different land qualities (fertile, average, poor) within the farm as perceived by the farmer (B), across the three sites in western Kenya selected for the study. HRE, MRE, LRE: high, medium and low resource endowment. Values on top of the bars indicate their standard deviation.

\subsection{Explaining maize yield variability}

\subsubsection{CART model 1: agronomic practices}

The optimum regression tree for maize grain yield as a function of management had eight terminal nodes (RE: 0.78) (Fig. 5). Resource use intensity (RUI) was the primary splitting node: average yields were $1.3 \mathrm{tha}^{-1}$ at low RUI (values $<1$, i.e. no, few or insufficient input use) and $2.3 \mathrm{t} \mathrm{ha}^{-1}$ at high RUI. At the second level in the hierarchy, the splitting criteria were delay in planting and planting density. At Splitting Node 2, early planted crops (relative delay $\leq 0.053 ; n=14$ ) had an average maize grain yield of $2.1 \mathrm{tha}^{-1}$ (TN 1), which is a good yield for the on-farm conditions prevailing in western Kenya (Tittonell et al., 2005 b), but late planted crops were the majority $(n=93)$ and gave smaller yields of average $1.2 \mathrm{tha}^{-1}$. High weed infestation in this group further reduced yields to $0.5 \mathrm{tha}^{-1}$ (TN2).

With high RUI, low planting density (Splitting Node 4) halved yields compared with high planting density. However, the three high yielding fields with maize planted at high density ( $>7.9$ plants $\mathrm{m}^{-2}$; TN8) constitute exceptional cases. Small yields in crops with high RUI planted at low to moderate densities were additionally associated with fields distant from homesteads. For fields close to homesteads, heavy Striga infestation reduced yields by $40 \%$. The low number of cases in TN7 and TN5 is due to the small number of cases in the data set where high resource intensities were observed in distant fields and where close fields, with medium or high resource use, were affected by Striga.

\subsubsection{CART model 2: integrating agronomic and environmental factors}

The full model including soil variables had similar higher level structure (top two levels) to the initial model that considered only agronomic practices (Fig. 6), indicating that these were the dominant variables influencing yields. The relative error of the model (RE: 0.79) was not reduced with respect to CART model 1. At low RUI, early-planted crops had smaller average yields at low soil $\mathrm{N}\left(<1.1 \mathrm{~g} \mathrm{~kg}^{-1}\right)$ than at high soil $\mathrm{N}$; whereas late-planted crops had smaller yields at very low Olsen $\mathrm{P}\left(<2 \mathrm{mg} \mathrm{kg}^{-1}\right)$ than at higher Olsen $\mathrm{P}$ concentrations. As in Model 1, at high RUI (right branch) denser crops $\left(>4.4 \mathrm{pl} \mathrm{m}^{-2}\right)$ performed better than sparser ones. The total soil $\mathrm{N}$ threshold of $1.1 \mathrm{~g} \mathrm{~kg}^{-1}$ is similar to the value used by Shepherd and Walsh (2002) to classify samples of an extensive library of African soils into soil quality classes. The splitting node 4 contained a large number of observations $(n=90)$. Such asymmetrical distribution of the observations, with the largest number of cases in TN 3 and TN 4 appeared to be realistic: late planted crops with low input use were the general case in the mid-distance to remote fields of the farms visited, and in those fields $\mathrm{P}$ availability tended to be low to extremely low. The larger number of observations with low $\mathrm{P}$ availability also stands out in Fig. 3 (zones II and III of the scatter plot).

\subsubsection{Site differences}

The variable 'Site', which aggregated climatic variability, agro-ecological and socio-cultural diversity, was not selected by CART as an explanatory variable in the models, suggesting that site effects were accounted for by the management variables. However, there were some interesting trends in management $\times$ site interactions (Table $2 \mathrm{a}$ ). For example, TN $1(n=21)$ had 14 cases from Aludeka, 5 from Emuhaya and 2 from Shinyalu. The splitting node $3(n=36)$ represents fields that were planted early, such as the home gardens, but cropped without nutrient inputs (particularly without manure). This is consistent with previous observations, as manure use is restricted in Aludeka as compared with the other sites for several reasons (i.e. a free grazing system that makes manure collection difficult, lack of knowledge on composting, small cattle population due to high incidence of tripanosomiasis). TN 1 is comprised of home gardens that are poor in total soil $\mathrm{N}$; this is more common in Aludeka, as most of the home gardens (the fields around the homestead) from Emuhaya and Shinyalu fell in the strata of the right-hand branch, high resource use intensity and soils that are consequently more fertile (cf. Fig. 6).

\subsubsection{Farmers' perception of soil fertility}

The observations stratified using CART analysis were cross-checked with the perception of soil quality of the 


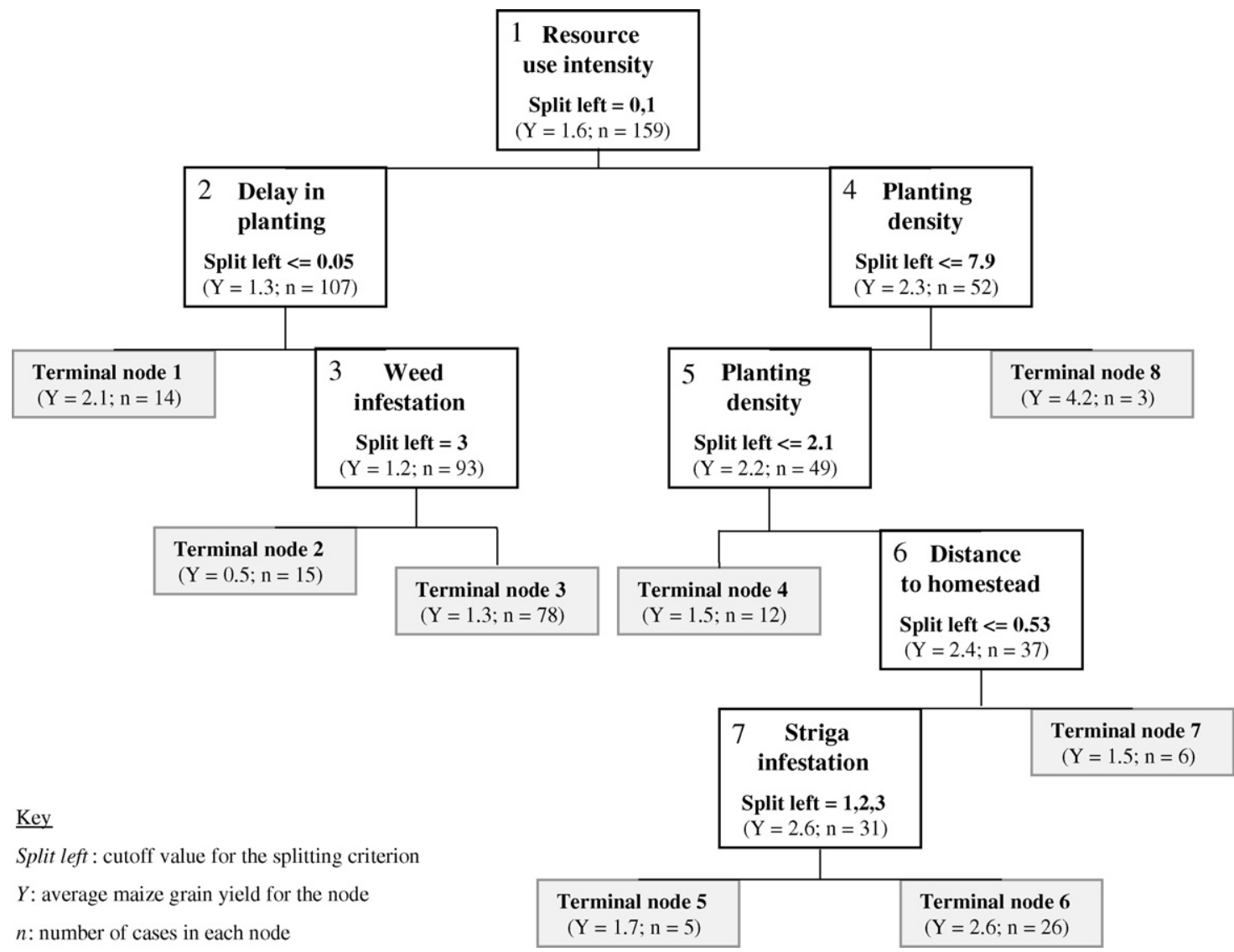

Fig. 5. Classification and regression tree model to describe maize grain yield variability as a function of variables representing agronomic management decisions (cf. Table 1). White boxes are splitting nodes ( $\mathrm{SN}$ ) and grey boxes are terminal nodes (TN). Within each SN the following information is given: the variable that splits the group of observations in two 'child' nodes, its threshold value and classification criterion (e.g. for SN 4 , split left $\leq 7.9$ means that all values with plant density $<$ or $=7.9$ are grouped in SN 5, to the left), the average maize yield of each group $(Y)$, and the number of observations in each group $(n)$. For the TN, only the two latter are given.

farmers (Table 2b). More than $50 \%$ of the fields that were cropped with high resource use intensity were perceived by farmers to be fertile at the three sites, and most of the fields perceived to be poor were planted late with few or no nutrient inputs. Average maize yields (Fig. 7), soil fertility (Table 3) and agronomic management (Table 4) indicators were calculated for each stratum. The yields corresponding to different strata were consistent across sites except for the

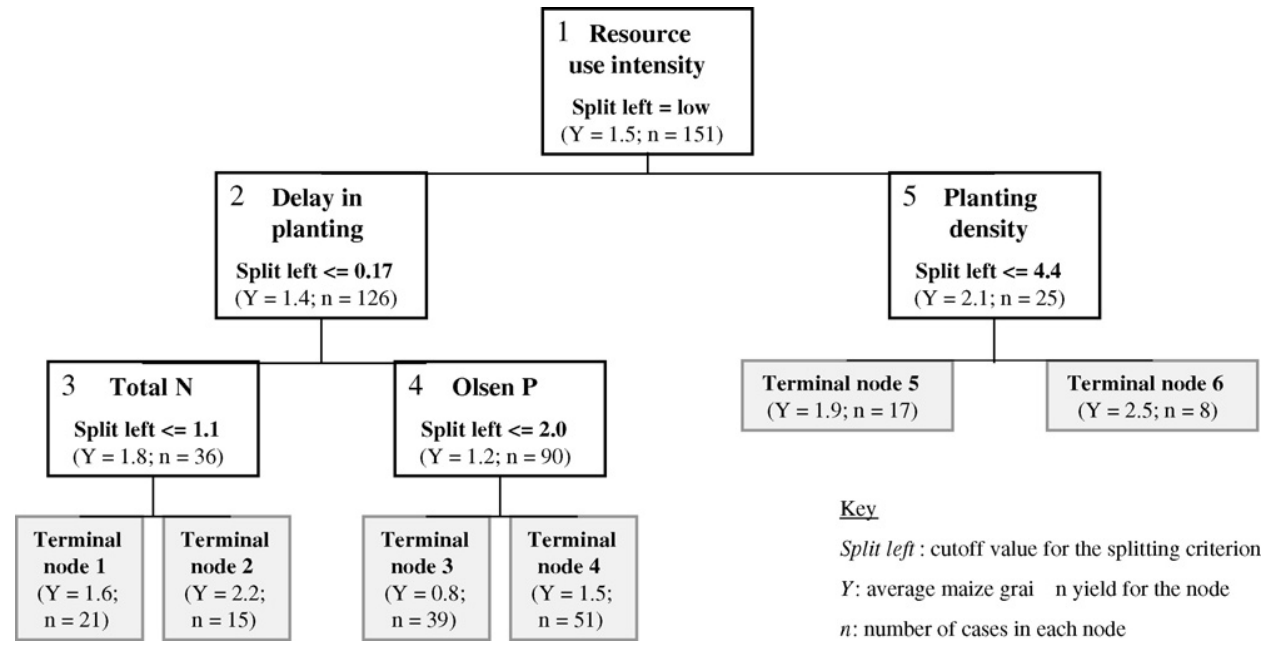

Fig. 6. Classification and regression tree model to describe maize grain yield variability as a function of variables representing agronomic management decisions plus environmental variables (cf. Table 1). See Fig. 5 for further explanation. 
Table 2

Distribution of observations falling: (a) within the classes identified by CART (model 2) across sites, and (b) correspondence between classes distinguished exclusively by management with the perception of soil fertility by farmers

\begin{tabular}{|c|c|c|c|c|c|c|c|c|}
\hline \multirow[t]{2}{*}{ Site $(n)$} & \multirow[t]{2}{*}{ Maize yield $\left(\mathrm{t} \mathrm{ha}^{-1}\right)$} & \multicolumn{7}{|c|}{ Number of observations per node } \\
\hline & & TN1 & $\mathrm{TN} 2$ & TN3 & TN4 & TN5 & & TN6 \\
\hline \multicolumn{9}{|l|}{ (a) } \\
\hline Aludeka (48) & $1.1 \pm 0.6$ & 14 & 1 & 20 & 11 & 2 & & 0 \\
\hline Emuhaya (52) & $1.7 \pm 0.9$ & 5 & 5 & 13 & 18 & 8 & & 3 \\
\hline Shinyalu (51) & $1.6 \pm 0.9$ & 2 & 9 & 6 & 22 & 7 & & 5 \\
\hline Management class & CART node & \multicolumn{2}{|c|}{ Fertile fields $(\%)$} & \multicolumn{2}{|c|}{ Average fields $(\%)$} & \multicolumn{3}{|c|}{ Poor fields $(\%)$} \\
\hline \multicolumn{9}{|l|}{ (b) } \\
\hline \multicolumn{9}{|l|}{ Low resource use } \\
\hline Planting early & SN3 & \multicolumn{2}{|c|}{28} & \multicolumn{2}{|c|}{28} & \multicolumn{3}{|c|}{9} \\
\hline Planting late & SN4 & \multicolumn{2}{|c|}{51} & \multicolumn{2}{|c|}{54} & \multicolumn{3}{|c|}{85} \\
\hline \multicolumn{9}{|l|}{ High resource use } \\
\hline Sparser crops & TN5 & \multicolumn{2}{|c|}{18} & \multicolumn{2}{|c|}{10} & \multicolumn{3}{|c|}{3} \\
\hline Denser crops & TN6 & \multicolumn{2}{|c|}{4} & \multicolumn{2}{|c|}{8} & \multicolumn{3}{|c|}{3} \\
\hline
\end{tabular}

SN: splitting node; TN: terminal node.

fields within TN 2 (corresponding to fields planted early, cropped with no or few inputs and having total soil $\mathrm{N}$ $>1.1 \mathrm{~g} \mathrm{~kg}^{-1}$ ) (Fig. 7B). Fields cultivated with high resource use intensity and planted with denser crop stands (TN 6) were present only in Emuhaya and Shinyalu (cf. Table 2a). They had less weed infestation and were located at intermediate distances from the homestead (Table 4). The poorest fields corresponded to $\mathrm{TN} 3$, with the lowest yields across sites, the smallest values for most soil fertility indicators, a less intense management, and a higher frequency of cases from Aludeka.

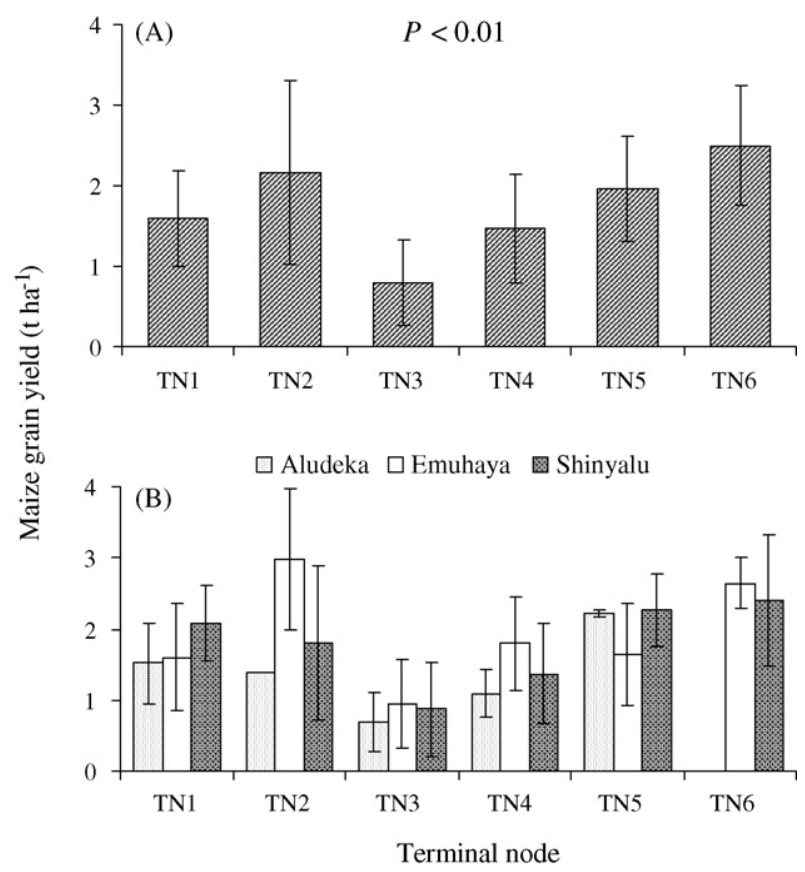

Fig. 7. Average and standard deviation of maize grain yields for each of the terminal nodes (TN1 to TN6) from the classification and regression tree model of Fig. 6(A), and the average and standard deviation for each TN discriminating by site (B). Lettering on top of the bars in (A) indicates the statistical significance of the differences between means $(P<0.01)$.

\subsection{Targeting fields with different soil qualities}

To target technology recommendations to soil fertility problem domains that farmers recognise and manage differently, it is necessary to identify recognisable thresholds of soil indicators. Soil $\mathrm{C}$ and available $\mathrm{P}$ are comprehensive indicators that varied quite independently from one field to another for the lower range of extractable P values (cf. PCA results-Section 2.3; cf. also Fig. 3), to which the majority of the soils sampled belong (cf. Splitting Node 4 in Fig. 6). Plotting maize grain yield against $\mathrm{C}$ and $\mathrm{P}$, and discriminating the observations that belong to the different CART strata, showed that the use of only these soil properties is insufficient to characterise yield variability within farms (Fig. 8). The variation in yields as affected by these soil properties is best characterised by boundary line relationships. To illustrate this, the dotted lines in Fig. 8 are simply 'hand-drawn' boundary lines considering only the observations in TN 3 and TN 4, which constitute the majority of the observations and are also those that are of most interest for targeting agronomic research. For low values of both soil $\mathrm{C}$ and available $\mathrm{P}$, maize yields were invariably low, while for higher values of these soil indicators yields may be high or low, depending on other factors (chiefly management factors). In particular, yield limitation by very low $\mathrm{P}$ availability when extractable $\mathrm{P}$ $<2 \mathrm{mg} \mathrm{kg}^{-1}$ appeared very clearly. The upper yield level achieved in fields belonging to TN 3 and TN $4\left(\mathrm{ca} .3 \mathrm{tha}^{-1}\right)$ may also be the result of factors that were unaccounted for in this study, such as the maize genotype.

\section{Discussion}

\subsection{Explaining variability in crop growth}

Crop growth performance is often assumed to be the first visual indication of the existence of spatial variability in soil 
Table 3

Average soil properties of the fields within each terminal node of CART model 2 (Fig. 6)

\begin{tabular}{|c|c|c|c|c|c|c|c|c|c|}
\hline Criteria & $\begin{array}{l}\text { Terminal } \\
\text { node }\end{array}$ & $\begin{array}{l}\text { Clay + silt } \\
(\%)\end{array}$ & $\begin{array}{l}\text { SOC } \\
\left(\mathrm{g} \mathrm{kg}^{-1}\right)\end{array}$ & $\begin{array}{l}\text { TSN } \\
\left(\mathrm{g} \mathrm{kg}^{-1}\right)\end{array}$ & $\begin{array}{l}\text { Olsen-P } \\
\left(\mathrm{mg} \mathrm{kg}^{-1}\right)\end{array}$ & $\begin{array}{l}\text { Exch. K + } \\
\left(\mathrm{cmol} \mathrm{kg}^{-1}\right)\end{array}$ & $\begin{array}{l}\text { ECEC } \\
\left(\mathrm{cmol} \mathrm{kg}^{-1}\right)\end{array}$ & $\begin{array}{l}\mathrm{pH} \text { water } \\
(1: 2.5)\end{array}$ & $\begin{array}{l}\text { Field } \\
\text { slope }(\%)\end{array}$ \\
\hline \multicolumn{10}{|l|}{ Low resource use } \\
\hline \multicolumn{10}{|l|}{ Early planting } \\
\hline $\mathrm{TSN}>1.1 \mathrm{~g} \mathrm{~kg}^{-1}$ & 1 & $49 \pm 5$ & $10.3 \pm 1.8$ & $0.7 \pm 0.2$ & $2.2 \pm 0.6$ & $0.35 \pm 0.3$ & $4.9 \pm 0.9$ & $5.6 \pm 0.4$ & $4 \pm 5$ \\
\hline $\mathrm{TSN}>1.1 \mathrm{~g} \mathrm{~kg}^{-1}$ & 2 & $67 \pm 11$ & $15.2 \pm 3.3$ & $1.4 \pm 0.2$ & $3.9 \pm 2.5$ & $0.38 \pm 0.2$ & $8.4 \pm 2.5$ & $5.6 \pm 0.5$ & $7 \pm 4$ \\
\hline \multicolumn{10}{|l|}{ Late planting } \\
\hline Olsen-P $<2.0 \mathrm{mg} \mathrm{kg}^{-1}$ & 3 & $47 \pm 13$ & $9.1 \pm 3.1$ & $0.6 \pm 0.4$ & $1.4 \pm 0.4$ & $0.18 \pm 0.1$ & $4.0 \pm 2.5$ & $5.2 \pm 0.4$ & $10 \pm 14$ \\
\hline Olsen-P $>2.0 \mathrm{mg} \mathrm{kg}^{-1}$ & 4 & $60 \pm 14$ & $13.1 \pm 3.7$ & $1.0 \pm 0.6$ & $3.1 \pm 1.3$ & $0.30 \pm 0.3$ & $7.3 \pm 3.0$ & $5.5 \pm 0.4$ & $8 \pm 10$ \\
\hline \multicolumn{10}{|l|}{ High resource use } \\
\hline Sparser crops & 5 & $56 \pm 14$ & $13.3 \pm 3.8$ & $1.1 \pm 0.4$ & $3.3 \pm 1.5$ & $0.24 \pm 0.2$ & $6.9 \pm 3.2$ & $5.6 \pm 0.5$ & $5 \pm 5$ \\
\hline Denser crops & 6 & $63 \pm 11$ & $14.6 \pm 3.0$ & $1.2 \pm 0.3$ & $3.5 \pm 1.2$ & $0.16 \pm 0.1$ & $7.3 \pm 2.3$ & $5.3 \pm 0.5$ & $8 \pm 8$ \\
\hline Standard error of the difference & & 4.6 & 1.23 & 0.17 & 0.39 & 0.09 & 1.00 & 0.15 & 3.6 \\
\hline$P<$ & & 0.001 & 0.001 & 0.001 & 0.001 & 0.014 & 0.001 & 0.001 & Ns \\
\hline
\end{tabular}

SOC: Soil organic carbon; TSN: total soil nitrogen; Olsen-P: extractable phosphorus; Exch. K+: exchangeable potassium; ECEC: effective cation exchange capacity.

fertility status within smallholder farms. However, soil fertility variables were subservient to crop management variables in the optimal CART model (cf. Fig. 6) and were only important at low levels of resource use intensity. Farmers appear to give priority to crop and soil management in the fields within their farms that they perceived to be fertile. Although farmers' management strategies can be proactive in some situations (Tabu et al., 2005), in this study farmers appeared to follow a reactive strategy (i.e. based on predetermined soil fertility). Thus soil heterogeneity determines crop yield variability not only through water or nutrient limitations, but also by influencing farmers' management decisions, which in turn feedback to reinforce the soil fertility patterns within farms.

The results of CART model 1 (Fig. 5) were in agreement with common field observations. First, when no or few resources are used, reasonably good yields can be produced if the crops are planted early on relatively good soils; in western Kenya, the first fields to be planted with maize are the home gardens, where maize cobs for roasting can be harvested early. The home gardens are often zones of nutrient concentration within the farm. Second, when nutrient inputs are used, the density of the crop stand becomes critical in determining maize yield (crop architecture). Farmers often adjust crop density to the perceived fertility of their soils, as seen in other areas of Africa (e.g. Mutsaers et al., 1995). Third, crops planted in distant fields normally produce poor yields even when nutrients are used, due to the poor soil quality of those fields, leading to weak crop responses to input use (cf. Wopereis et al., 2006). Fourth, Striga infestation is a more important factor that reduces yields of crops that receive nutrient inputs and are planted in close fields, compared with poor crops grown in remote fields, despite the greater prevalence of Striga in remote fields.

Table 4

Average values of several crop management variables for each of the terminal nodes in CART model 2 (Fig. 6)

\begin{tabular}{|c|c|c|c|c|c|c|c|}
\hline Criteria & $\begin{array}{l}\text { Terminal } \\
\text { node }\end{array}$ & $\begin{array}{l}\text { Distance to } \\
\text { homestead }^{\text {a }}\end{array}$ & $\begin{array}{l}\text { Resource use } \\
\text { intensity }\end{array}$ & $\begin{array}{l}\text { Delay in } \\
\text { planting }(d)\end{array}$ & $\begin{array}{l}\text { Plant density } \\
\left(\mathrm{pl} . \mathrm{m}^{-2}\right)\end{array}$ & $\begin{array}{l}\text { Weed infestation } \\
\text { level }^{c}\end{array}$ & $\begin{array}{l}\text { Striga infestation } \\
\text { level }^{c}\end{array}$ \\
\hline \multicolumn{8}{|l|}{ Low resource use } \\
\hline \multicolumn{8}{|l|}{ Early planting } \\
\hline $\mathrm{TSN}<1.1 \mathrm{~g} \mathrm{~kg}^{-1}$ & 1 & 0.34 & 0.5 & 3 & 3.0 & 1.1 & 0.3 \\
\hline $\mathrm{TSN}>1.1 \mathrm{~g} \mathrm{~kg}^{-1}$ & 2 & 0.46 & 0.6 & 5 & 2.9 & 1.1 & 0.0 \\
\hline \multicolumn{8}{|l|}{ Late planting } \\
\hline Olsen-P $<2.0 \mathrm{mg} \mathrm{kg}^{-1}$ & 3 & 0.51 & 0.3 & 32 & 2.5 & 1.8 & 0.6 \\
\hline Olsen-P $>2.0 \mathrm{mg} \mathrm{kg}^{-1}$ & 4 & 0.54 & 0.4 & 27 & 3.2 & 1.3 & 0.2 \\
\hline \multicolumn{8}{|l|}{ High resource use } \\
\hline Sparser crops & 5 & 0.33 & 2.4 & 10 & 3.4 & 1.1 & 0.4 \\
\hline Denser crops & 6 & 0.41 & 2.4 & 19 & 5.6 & 0.8 & 0.1 \\
\hline Standard error of the difference & & 0.09 & 0.19 & 4.1 & 0.54 & 0.33 & 0.26 \\
\hline$P<$ & & 0.005 & 0.001 & 0.001 & 0.001 & 0.005 & 0.008 \\
\hline
\end{tabular}

\footnotetext{
${ }^{\text {a }}$ Expressed in relative terms (distance to the homestead/maximum distance within the farm, cf. Table 1).

b Average values for the score: 0 , no use to 3 , high use intensity.

c Average values for the score: 0 , no infestation to 3 , high infestation.
} 

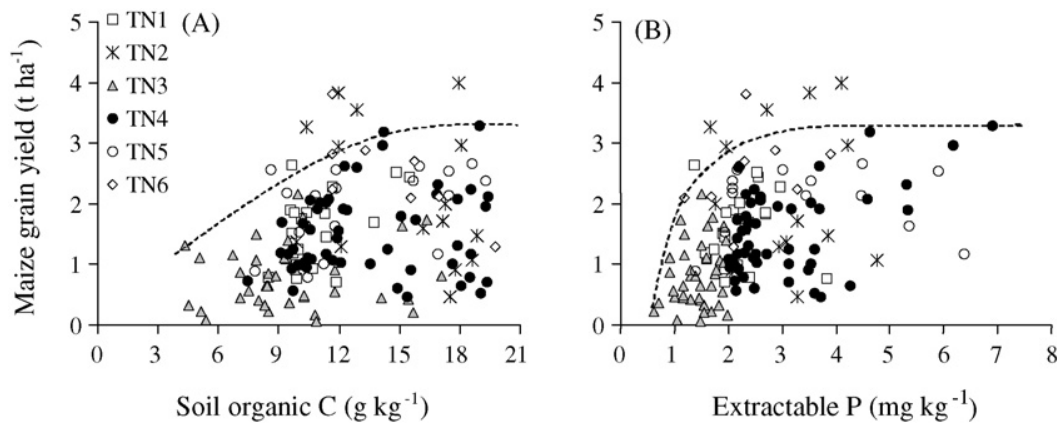

Fig. 8. Maize grain yield as a function of soil C (A) and extractable P (B). Different symbols indicate observations that were classified within different terminal nodes (TN1 to TN6) in the CART analysis. The dotted lines were 'hand drawn' to represent the upper boundary of the observations corresponding to TN3 and TN4. Soil data correspond to spectral predictions.

The observations grouped in TN 3 and TN4 of CART model 2 (Fig. 6) were the most numerous and corresponded to fields cropped with few or no inputs, planted late (up to 1 month later than the recommended planting dates, Table 4) and at large relative distances from the homestead $(\mathrm{RDH})>0.5$. Yields in the TN 3 and TN 4 ranged around $1 \mathrm{tha}^{-1}$-an average reference yield for the highlands of East Africa (e.g. Mugendi et al., 1999) but well below the maximum yields attained in controlled experiments in western Kenya (FURP, 1994). TN 3 grouped maize yield observations corresponding to values of extractable $\mathrm{P}$ in the soil $<2 \mathrm{mg} \mathrm{kg}^{-1}$; such soils tended to be also poor in organic $\mathrm{C}$ (Fig. 8). An extractable (Olsen) $\mathrm{P}$ value of $2 \mathrm{mg} \mathrm{kg}^{-1}$ may be considered a threshold between 'extremely poor' and 'poor' soils in terms of P availability (Young, 1997)—note in Fig. 8 that some grain yields corresponding to TN 3 were almost nil. Vanlauwe et al. (2006) derived a threshold of $7 \mathrm{mg} \mathrm{kg}^{-1}$ extractable $\mathrm{P}$ for maize responses to applied $\mathrm{P}$ in western Kenya. However, the relative response to $\mathrm{P}$ in fields with less than $7 \mathrm{mg} \mathrm{g}^{-1} \mathrm{P}$ in that study varied from 0.2 to 1.2 . Such variability cannot be ascribed only to $P$ availability but to the existence of multiple-limiting factors operating simultaneously.

The terminal nodes from the CART analysis define problem domains to which specific intervention strategies can be targeted. For example, the yield gap between TN 5 and TN 6 could be simply bridged by improved agronomy (i.e., establishing proper plant stands in this case), whereas TN 3 and TN 4 would require major soil rehabilitation including addition of $\mathrm{P}$ and organic matter. These results, however, may be affected by climatic variability. Although the amount of rainfall registered during the long rains of 2002 was close to the average value for each site (i.e. neither drought nor excess rainfall were registered), inter-annual rainfall variability may affect not only the average maize yields but also the relative influences of the various factors determining maize productivity. The regional variation in average rainfall is also closely related to the variation in soil types across sites (cf. Fig. 2). Finer soil textures in a cooler and wetter climate lead to greater contents of organic $\mathrm{C}$ in the soils in Shinyalu, where all fields had values $>14 \mathrm{~g} \mathrm{~kg}^{-1}$, notably larger than all fields from the other two sites. Although this does not necessarily translate into larger average yields (cf. Fig. 4), most of the observations in the highest yielding groups TN 2 and TN 6 were from Shinyalu (Fig. 7, Table 2a). These observations correspond to home fields managed with (TN 6) or without (TN 2) inputs, but with (relatively) fertile soils (cf. Table 3).

\subsection{Reconciling soil quality categories with local knowledge}

Farmers' perception of soil quality 'niches' cannot be reconciled directly with the usual indicators of soil fertility such as soil C and nutrient contents (cf. Table 3, Fig. 7), despite methodologies designed to support this approach (e.g. Barrios et al., 2001). In the first place, because of the co-existence of multiple nutrient limitations, farmers perceive soils as having low or high productivity regardless of their main limitation; the concept of limiting nutrients for plant growth appears too abstract to farmers (Tittonell et al., 2005d). During our field assessments, farmers had a more holistic definition of 'suitability niches' to which they allocated their production activities and resources within their farms. Suitability not only considers soil fertility but also other field characteristics such as soil depth, proximity to woodlots (shading), type of fencing to protect the crop from roaming livestock, the slope and the relative position of the field within the farm; i.e. crops grown in remote fields are more prone to theft. In this sense, the definition of the variable 'relative distance to homestead' (RDH) as a 'management' factor in the CART analysis may be questionable. In the heavily-dissected landscape of western Kenya, the slope of the fields tends to increase with increasing distance from the homestead and soil types naturally vary for fields located at different positions in the catena (Tittonell et al., 2005c). At the same time, the effort to carry bulky materials such as manure or compost to fertilise crops planted far from the homestead is even larger due to the steep slope of these fields. Thus, the interrelationship 'distance from the homestead - soil management - current soil fertility' is complex in the farms of western Kenya. 
Although the categorisation of field types according to their location within the farm (e.g. close versus remote fields) may be practical for certain studies, its arbitrariness makes it less useful to communicate with farmers when attempting to target recommendations.

\subsection{CART analysis}

CART analysis allowed us to: (i) unravel interactions and combined effects in a complex dataset; (ii) identify thresholds in the relationship between maize yield and different soil and management variables; (iii) define problem domains for targeting different intervention strategies. The approach provided insight into the structure of interrelationships within the dataset more easily than if multiple regression modelling had been used, and obviated the need for data transformations and use of dummy variables to satisfy assumptions required by parametric approaches. The in-built cross-validation routine helped to ensure only robust predictive models were selected. Although some subjective decisions were required, such as defining cut-off values for dividing variables into discrete classes, and defining the acceptable error in the final model, these decisions are also required with more conventional statistical modelling approaches: they should be made explicit. Alternative models that provide a similar degree of predictive power (i.e. relative error) could also be explored to increase insights into yield limiting factors.

\section{Summary and conclusions}

Soil fertility variability within smallholder farms determines farmers' management strategies and resource allocation among farm fields, with more nutrients, labour and other inputs being apportioned to the most fertile fields. Over time these resource allocation patterns feed back to positively reinforce the spatial variation in soil fertility. In our study, fields that were considered by farmers as poor in fertility (which were invariably low in soil extractable P) were managed with few or no inputs and planted late. These fields represent the majority of the farming area in western Kenya and need to be targeted with major rehabilitation strategies to improve land productivity and rural livelihoods. Such rehabilitation strategies will not, however, translate into improved crop productivity unless accompanied by improvements in agronomic practices, such as planting density and timeliness of planting and weeding. Farmers already apply more inputs to their most fertile fields for which only soil fertility maintenance strategies are required. Use of CART in relation with systematic surveys of agronomic practice provided a useful approach for analysing crop production constraints and targeting of intervention strategies. This approach could be adapted to provide a tool for monitoring the impact of intervention programmes designed to improve farm productivity.

\section{Acknowledgements}

We thank the European Union for funding through the AfricaNUANCES Project (Contract no INCO-CT-2004003729), and the Bundesministerium fur Wirtschaftliche Zusammenarbeit und Entwicklung (BMZ) for financial support through the project 'Improving Integrated Nutrient Management Practices on Small-scale Farms in Africa'.

\section{References}

Anderson, J.M., Ingram, J.S.I., 1993. Tropical Soil Biology and Fertility: A Handbook of Methods. CAB International, Wallingford, UK, pp. 221.

Barrios, E., Bekunda, M., Delve, R.J., Esilaba, A., Mowo, J., 2001. Identifying and Classifying Local Indicators of Soil Quality. Eastern Africa Version. Participatory Methods for Decision Making in Natural Resource Management. CIAT-SWNM-TSBF-AHI, Nairobi, Kenya.

Braun, A.R., Smaling, E.M.A., Muchugu, E.I., Shepherd, K.D., Corbett, J.D., 1997. Maintenance and Improvement of Soil Productivity in the Highlands of Ethiopia, Kenya, Madagascar and Uganda: An Inventory of Spatial and Non-spatial Survey and Research Data on Natural Resources and Land Productivity (African Highlands Initiative Technical Report Series No. 6). International Centre for Research in Agroforestry, Nairobi, Kenya.

Breiman, L., Friedman, J.H., Olshen, R.A., Stone, C.J., 1984. Classification and Regression Trees. Chapman and Hall (Wadsworth, Inc.), New York, US, pp. 254.

Crichton, N.J., Hinde, J.P., Marchini, J., 1997. Models for diagnosing chest pain: Is CART helpful? Stat. Med. 16, 717-727.

De Wit, C.T., 1992. Resource use efficiency in agriculture. Agric. Syst. 40, $125-151$.

FURP, 1994. Final Report of the Fertiliser Use Recommendation Program (FURP) Volumes V and VII Busia and Kakamega Districts. National Agricultural Research Laboratory, Kenya Ministry of Agriculture and Livestock, Nairobi, Kenya.

Gee, G.W., Bauder, J.W., 1986. Particle-size analysis. In: Klute, A. (Ed.), Methods of Soil Analysis. Part 1. second ed. Agron. Monog., vol. 9. ASA, CSSA, SSSA, Madison, Wisconsin, pp. 383-411.

Jaetzold, R., Schmidt, H., 1982. Farm Management Handbook of Kenya, Natural Conditions and Farm Management Information. Part A: West Kenya, vol. 2. Kenya Ministry of Agriculture, Nairobi, Kenya.

Kenya Ministry of Agriculture and Rural Development, 2004. Annual Reports for Vihiga, Kakamega and Teso districts: Surveys on Population and Agricultural Production 2004.

Martius, C., 2004. Assessing the sustainability of agroforestry systems using CART to model non-linear relationships. In: CART Data Mining Conference. San Francisco, CA, May 22-24 (available at: http:// www.salford-systems.com/).

Mugendi, D.N., Nair, P.K.R., Mugwe, J.N., O’Neil, M.K., Woomer, P.L., 1999. Calliandra and leucaena alley cropping with maize. I. Soil fertility changes and maize production in the sub-humid highlands of Kenya. Agrof. Syst. 46, 39-50.

Mutsaers, H.J.W., Adekunle, A.A., Walker, P., Palada, M.C., 1995. The Maize and Cassava Production System in Southwest Nigeria and the Effect of Improved Technology. On-farm trials in Alabata and Ayepe, 1985-1989. Resource and Crop Management Research Monograph No. 18. International Institute of Tropical Agriculture, Ibadan, Nigeria, pp. 50.

Nkonya, E., Kaizzi, C., Pender, J., 2005. Determinants of nutrient balances in a maize farming system in eastern Uganda. Agric. Syst. 85, 155-182.

Samaké, O., Smaling, E.M.A., Kropff, M.J., Stomph, T.J., Kodio, A., 2006. Effects of cultivation practices on spatial variation of soil fertility and millet yields in the Sahel of Mali. Agric. Ecosyst. Environ. 109, 335-345. 
Shepherd, K.D., Walsh, M.G., 2002. Development of reflectance spectral libraries for characterization of soil properties. Soil Sci. Soc. Am. J. 66, 988-998.

Shepherd, K.D., Palm, C.A., Gachengo, C.N., Vanlauwe, B., 2003. Rapid characterization of organic resource quality for soil and livestock management in tropical agroecosystems using near-infrared spectroscopy. Agron. J. 95, 1314-1322.

Shepherd, K.D., Walsh, M.G., 2007. Infrared spectroscopy-enabling an evidence-based diagnostic surveillance approach to agricultural and environmental management in developing countries. J. Near Infrared Spectrosc. 15, 1-19.

Steadman, H.J., Silver, E., Monahan, J., Apelbaum, P.S., Robbins, P.C., Mulvey, E.P., Grisso, T., Roth, L.H., Banks, S., 2000. A classification tree approach to the development of actuarial violence risk assessment tools. Law Human Behav. 24, 83-100.

Steinberg, D., Cola, P., 1997. CART-Classification and Regression Trees. Salford Systems, San Diego, CA.

Tabu, I.M., Obura, R.K., Bationo, A., Nakhone, L., 2005. Effect of farmers' management practices on soil properties and maize yield. J. Agron. 4, $1-7$.

Tittonell, P., Vanlauwe, B., Leffelaar, P.A., Giller, K.E., 2005a. Estimating yields of tropical maize genotypes from non-destructive, on-farm plant morphological measurements. Agric. Ecosyst. Environ. 105, 213-220.

Tittonell, P., Vanlauwe, B., Leffelaar, P., Rowe, E., Giller, K., 2005 b. Exploring diversity in soil fertility management of smallholder farms of western Kenya I. Heterogeneity at region and farm scales. Agric. Ecosyst. Environ. 110, 149-165.

Tittonell, P., Vanlauwe, B., Leffelaar, P.A., Shepherd, K.D., Giller, K.E., 2005c. Exploring diversity in soil fertility management of smallholder farms in western Kenya. II. Within-farm variability in resource allocation, nutrient flows and soil fertility status. Agric. Ecosyst. Environ. 110, 166-184.

Tittonell, P., Misiko, M., Ekise, I., Vanlauwe, B., 2005d. Feeding-back the result of soil research: the origin, magnitude and importance of farmerinduced soil fertility gradients in smallholder farm systems. In: Report on the Discussion Meetings at Emanyonyi Farmer Field School, Vihiga, Western Kenya, July 27, August 17 of 2005, Tropical Soil Biology and Fertility Institute of the International Centre for Tropical Agriculture (TSBF-CIAT), Nairobi, Kenya, pp. 23.

Tittonell, P., Vanlauwe, B., de Ridder, N., Giller, K.E., 2007. Heterogeneity of crop productivity and resource use efficiency within smallholder Kenyan farms: soil fertility gradients or management intensity gradients? Agric. Syst. 94, 376-390.

Tsien, C.L., Fraser, H.S., Long, W.J., Kennedy, R.L., 1998. Using classification tree and logistic regression methods to diagnose myocardial infarction. Medinfo 9, 493-497.

Van Asten, P.J.A., 2003. Soil Quality and Rice Productivity Problems in Sahelian Irrigation Schemes. Ph.D. Thesis. Wageningen University, ISBN 90-5808-852-9, Wageningen, The Netherlands, 143 pp.

Vanlauwe, B., Tittonell, P., Mukalama, J., 2006. Within-farm soil fertility gradients affect response of maize to fertilizer application in western Kenya. Nutr. Cycl. Agroecosyst. 76, 171-182.

Vanlauwe, B., Giller, K.E., 2006. Popular myths around soil fertility management in sub-Saharan Africa. Nutr. Cycl. Agroecosyst. 116, 34-46.

Wopereis, M.C.S., Tamélokpo, A., Ezui, K., Gnakpénou, D., Fofana, B., Breman, H., 2006. Mineral fertilizer management of maize on farmer fields differing in organic inputs in the West African savanna. Field Crop Res. 96, 355-362.

Young, A., 1997.In: Agroforestry for Soil Management. second ed. CAB International, New York, NY, p. 320. 